\title{
La participación adolescente. Deconstruyendo el adultocentrismo
}

\section{Celsa Garcia Pozo'}

\section{Universidad Autónoma Metropolitana-Xochimilco, Mexico}

\section{Reseña de libro}

Hernández Horta, G. (2017). Guía de Participación para adolescentes. México: INESIPINNA-UNICEF, disponible en: https://infosipinna.org/media/documentos/GUÍA_ADOLESCENTES.pdf Consulta: 22-012018.

Material original autorizado para su primera publicación en el Journal de Ciencias Sociales, Revista Académica de la Facultad de Ciencias Sociales de la Universidad de Palermo.
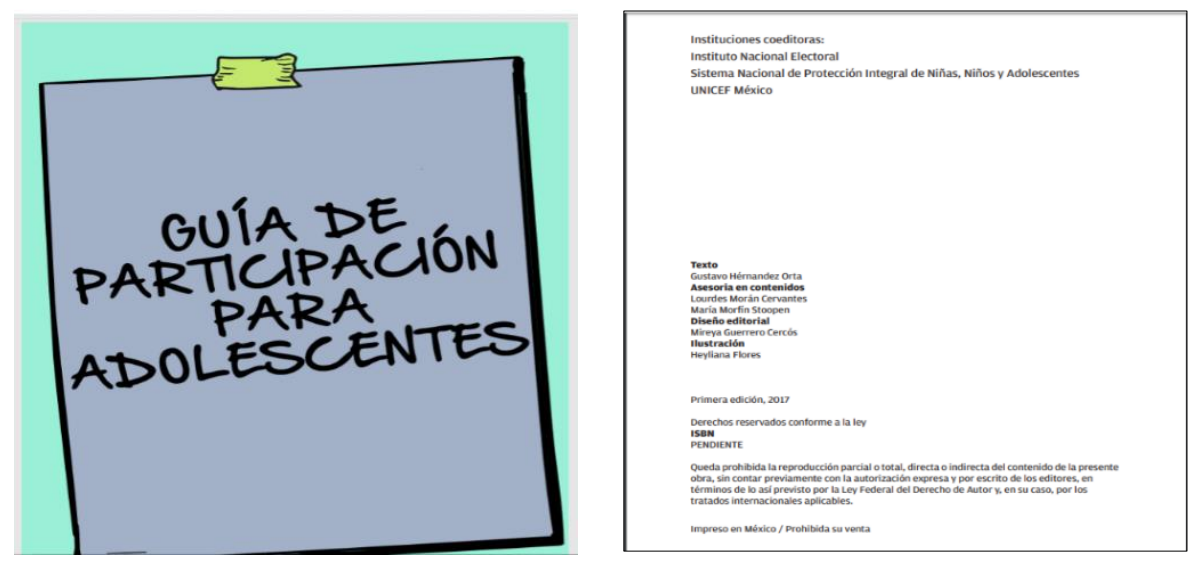

Resumen: El material denominado "Guía de Participación para adolescentes", es un esfuerzo de coedición de dos instituciones gubernamentales: el Sistema Nacional de Protección Integral de Niñas, Niños y Adolescentes, el Instituto Nacional Electoral y UNICEF; la articulación de instituciones es, en sí misma, un punto a favor para procesos de participación activa; por esta razón el interés de hacer una reseña del material, pues la voluntad de construcción horizontal debe de ser una realidad cotidiana.

A través de la reseña se identifica que La Guía de Participación para Adolescentes tiene una estructura sencilla donde cada uno de los capítulos puede ser trabajado de manera independiente o de forma consecutiva y "atrapa" al adolescente con un formato amable, y

\footnotetext{
${ }^{1}$ Psicologa (UNAM), integrante del equipo de trabajo de Programa Infancia (UAM) campus Xochimilco en el cual se desarrolla investigación sobre diferentes temáticas sobre infancias. Es fundadora y Directora de Asociación Civil Profesionistas Ante la Violencia Intrafamiliar y Sexual (PAVIS,A.C.).

Correo electrónico: pavis_3@yahoo.com.mx
} 
donde las actividades promueven la reflexión y la vinculación con sus entornos inmediatos, la interacción con sus pares y la horizontalidad de las relaciones.

\section{Introducción}

Al encontrarnos en un mar de información del mundo cibernético, acceder a materiales que aborden el trabajo de las Infancias desde la participación infantil y derechos de la infancia es de gran importancia: materiales que construyan conceptos para facilitar iniciativas, acciones que de manera ideal aterricen en la vida cotidiana y en particular en aquellas que impacten en la vida de los niños, niñas y adolescentes (NNA)

Tal es el caso de la Guía de Participación para adolescentes, que coeditaron dos instituciones gubernamentales: el Sistema Nacional de Protección Integral de Niñas, Niños y Adolescentes, el Instituto Nacional Electoral y UNICEF en un ejercicio de voluntades que coloca a niñas, niños y adolescentes como actores sociales competentes y sobre todo como sujeto de derechos. La población adolescente históricamente ha sido invisibilizada o peor aún cooptada y utilizada con el fin de legitimar su quehacer, en participaciones simuladas o manipuladas por intereses políticos, de mercado o de proselitismo ideológico de algún tipo.

A diferencia de otros manuales que están dirigidos a los facilitadores, profesores o a promotores adultos y no contemplan la posibilidad de trabajo entre pares, resalto que la presente Guía, permite que el adolescente sea el protagonista.

El diseño integral de la Guía es a color y consta de un formato media carta, está formado por 133 páginas a las que se le suma un colofón, haciéndolo un formato más amable y ligero para el tipo de público al que va dirigido. Es un Libro de actividades didácticas, en el cual, el lector puede desarrollar lo aprendido de la lectura por medio de las actividades, e interactuar con el material plasmando en él.

Las actividades no solo permiten amenizar la comprensión de la lectura, sino que el uso profuso de imágenes las refuerza y lo complementan con frases cortas o palabras claves. Los gráficos utilizados, son sencillos, de colores brillantes lo que permite generar en el lector aún más interés en el material. Cuenta también con estadísticas que apuntalan información con base a una consulta infantil y juvenil en el 2012.

\section{Comentarios}

Se invita a los adolescentes al conocimiento y a la acción como eje rector, donde el compartir información se constituye en un primer ejercicio de empoderamiento, ejercicio de congruencia para con la población lectora adolescente, elemento clave en el inicio de un proceso de toma de decisiones. Como proceso de aprendizaje, llevar la información a la acción social permite una experiencia integral, que rebasa el ámbito teórico, del "deber ser", 
de la "utopía". La construcción del conocimiento no puede disociarse del plano social, de la interacción para incidir en la transformación misma de la práctica y de la realidad.

Con respecto a los destinatarios, en la lectura encontramos un lenguaje cotidiano que facilita la cercanía texto-lector donde "lo social" ubica en un primer momento un NOSOTROS incluyente, que define como destinatarios a las y los adolescentes, sector que con frecuencia se olvida al incorporarlo en la categoría de niños y niñas, o bien al segmentarlos como parte de la juventud o con distintas responsabilidades penales según el rango de edad.

Y en este tenor, la Guía se aparta del tono individualista ya que no supone un lector solitario sino habla de grupo (s) y alianzas para trabajar como punto de partida. Es pues un enfoque interesante que ubica a los sujetos como nodos de relación y no como entes a ser socializados. Las referencias a la comunicación y al diálogo como herramientas que facilitan la convivencia "horizontal" a incluir en lo cotidiano, desplazan la idea de un orden preconcebido, rígido que no puede cambiarse: “...Y la mejor forma de tener buena comunicación, hasta donde se sabe, es a través del diálogo, que es la manera en que se crean las reglas y normas para convivir..." (p.10)

En esta sencilla propuesta coloquial se establecen las posibles bases para la deconstrucción de procesos hegemónicos, en términos de la Guía planteado como "apropiarnos del espacio público, es decir tomar decisiones que nos favorezcan a todos" y animar a la deconstrucción de un imaginario adultocentrista, en donde él o la adolescente no tendría nada que hacer.

Por todo lo anterior, hago notar la importancia de este movimiento de acción ciudadana que presenta alternativas al o a la adolescente que incorporan estos criterios delimitadores de conducta: "que sí, o que no se debe hacer". El disenso, la duda, la posibilidad de evaluar estos criterios quedan fuera del discurso adultocéntrico tradicional, quedándole como opción "saltarse las trancas", ignorando estas normas y buscando complicidades con sus pares. El diálogo y la participación por otro lado, obliga a situarse como interlocutor(a) dentro del campo normativo en la toma de decisiones en las esferas en que se mueve (familia, escuela, amistades) y la Guía hace un llamado explícito a esta nueva oportunidad, brindada por una serie de derechos y libertades concretas, y formuladas en frases cortas y específicas que hacen referencia al respeto a la pluralidad y la diversidad de todo tipo (p. 13)

Tu derecho a participar como lema promueve la reflexión de su propia acción a través de diferentes preguntas, ubicando el ámbito de su acción en la vida comunitaria y destacando los espacios comunes y públicos que les permitirá ubicarse en un espacio-temporal particular, pues la respuesta requiere un aquí y ahora, pero llevándolos después a un recorrido histórico que marque el "antes " del reconocimiento de derechos y la construcción del montaje institucional necesario para garantizar "tu derecho a participar". 
El capítulo "En la escuela" se propone a los y las adolescentes, tener un papel más activo como proponer temas de interés por aprender o actividades o solicitar clases especiales, es decir activar la llamada autonomía curricular; lo que en el contexto mexicano es complejo. Sin embargo, existe la figura de los Consejos Escolares de Participación Social como espacios coyunturales en formato de asamblea, que de manera progresiva se conviertan en una estrategia de toma de decisiones colectivas.

La decisión de participar implica comprender, vivir, llevar a la realidad cotidiana el proceso de autonomía progresiva en un círculo virtuoso en que sus experiencias de participación redundarán en el desarrollo de sus diferentes capacidades, lo que a su vez facilitará y fortalecerá cada vez más temas y decisiones en los que quieran intervenir, deconstruyendo así un pensamiento hegemónico y colonizador que se atribuye la facultad de definir de manera excluyente a quienes se les faculta para la toma de decisiones por cubrir ciertas características.

La Guía facilita que los y las adolescentes reflexionen que no solo basta el deseo del participar, pensar, expresarse, dialogar, decidir y/o actuar, pues es relevante identificar y concientizar los diferentes elementos o condiciones que han frenado estas capacidades para la participación, es decir el autoconocimiento, lo que implica un proceso de confianza no lineal y complejo que clarifique su posible quehacer desde la participación y construya vínculos de reciprocidad y solidaridad.

En la Guía en el capítulo "Las personas con las que vives", matiza entre líneas el respeto a las diferencias, donde la empatía como virtud facilita "transitar" en el espacio público. Considerar que la diferencia es una opción y no un problema; escuchar de una manera activa y comprender que en y desde la diferencia, sí, es posible dialogar y encontrar soluciones para actuar con respeto, marca la importancia del otro, y descentra el protagonismo en un solo actor, pues sin el otro no hay participación.

La diferencia como una posibilidad de construcción, será siempre protegida por los llamados "acuerdos". En la Guía hacen notar que algunos temas o problemas a resolver les puede llevar a provocar reacciones poco cordiales. El formato sugerido para llegar a acuerdos es la asamblea, lo que difícilmente se realiza en la cotidianidad y en particular en una organización social vertical y adultocéntrica, tema pendiente a trabajar.

"Conocer tus derechos" se hace equivalente a ser un buen jugador, pero a diferencia de algunos juegos en donde hay perdedores que salen del juego, se alude a un principio importante: los derechos no se sujetan a deberes y obligaciones "...los derechos humanos son inalienables, es decir, nadie puede ser despojado o excluido de ellos..." (p.48) tema fundamental, pues es frecuente en el discurso adultocéntrico de condicionar el derecho con un deber. 
En la Guía se toca el tema de las distintas expresiones de violencia, donde hacerse escuchar, levantar la voz es también una forma activa de participación válida y necesaria. La denuncia promueve encontrar apoyos, soluciones a conflictos que se pueden mirar como irresolubles comprometiéndose la calidad de convivencia que lastima a muchos integrantes de la comunidad estudiantil.

Los diferentes escenarios comunitarios a los cuales tiene acceso un(a) adolescente tanto en espacios público como privado, establece relaciones complejas con los actuales "espacios comunitarios virtuales", tema a trabajar en donde se recomienda explorarlos con la orientación adulta experta.

En la página 60 de la Guía se solicita elaborar un mapa de su comunidad; este es un ejercicio ideal que da la oportunidad de tomar conciencia de su entorno y reflexionarlo; mejor aún transformarlo y darle un sentido diferente, tejiendo redes sociales.

Sobre el capítulo "¿Jugamos? Divertirse y descansar también es participar", se propone desvincular a la participación como mero instrumento de la productividad capitalista ya que en esta particular etapa de la vida el "uso del tiempo" se queda atrapada en la importancia de la inversión para "su" futuro.

\section{Conclusiones:}

Recomiendo el uso de la guía, al ser un material donde se promueve la participación, donde él y la adolescente puedan construir su propio proceso a través de reflexión y de las actividades que los y las lleve a la acción comunitaria, animándolos a vincularse con su entorno inmediato desde una autonomía progresiva.

En la construcción de relaciones horizontales en sus entornos a partir del conocimiento de sus derechos e información, no solo desde una teoría, sino desde la vida cotidiana, este tipo de materiales merecen ser difundidos, con la bondad de ser enriquecido al retroalimentarse con las experiencias de los adolescentes participantes. 